\title{
NeOProM: Neonatal Oxygenation Prospective Meta-analysis Collaboration study protocol
}

Lisa M Askie ${ }^{1 *}$, Peter Brocklehurst ${ }^{2}$, Brian A Darlow ${ }^{3}$, Neil Finer ${ }^{4}$, Barbara Schmidt ${ }^{5,6}$, William Tarnow-Mordi ${ }^{7,8}$, for the NeOProM Collaborative Group ${ }^{1}$

\begin{abstract}
Background: The appropriate level of oxygenation for extremely preterm neonates ( $<28$ weeks' gestation) to maximise the greatest chance of survival, without incurring significant morbidity, remains unknown. Infants exposed to lower levels of oxygen (targeting oxygen saturations of $<90 \%$ ) in the first weeks of life are at increased risk of death, cerebral palsy, patent ductus arteriosus, pulmonary vascular resistance and apnoea, whilst those maintained in higher levels of oxygen (targeting oxygen saturations of $>90 \%$ ) have been reported to have greater rates of morbidity including retinopathy of prematurity and chronic lung disease. In order to answer this clinical dilemma reliably, large scale trial evidence is needed.

Methods/Design: To detect a small but important 4\% increase in death or severe disability in survivors, over 5000 neonates would need to be recruited. As extreme prematurity affects $1 \%$ of births, such a project undertaken by one trial group would be prohibitively lengthy and expensive. Hence, the Neonatal Oxygenation Prospective Meta-analysis (NeOProM) Collaboration has been formed. A prospective meta-analysis (PMA) is one where studies are identified, evaluated, and determined to be eligible before the results of any included studies are known or published, thereby avoiding some of the potential biases inherent in standard, retrospective meta-analyses. This methodology provides the same strengths as a single large-scale multicentre randomised study whilst allowing greater pragmatic flexibility. The NeOProM Collaboration protocol (NCT01124331) has been agreed prior to the results of individual trials being available. This includes pre-specifying the hypotheses, inclusion criteria and outcome measures to be used. Each trial will first publish their respective results as they become available and the combined meta-analytic results, using individual patient data, will be published when all trials are complete. The primary outcome to be assessed is a composite outcome of death or major disability at 18 months - 2 years corrected age. Secondary outcomes include several measures of neonatal morbidity. The size of the combined dataset will allow the effect of the interventions to be explored more reliably with respect to pre-specified patientand intervention-level characteristics.
\end{abstract}

Discussion: Results should be available by 2014.

\section{Background}

Extreme prematurity of less than 28 weeks' gestation affects approximately $1 \%$ of births [1]. Although $80 \%$ of these infants are discharged home alive [2], they often sustain severe morbidity [3], including chronic lung disease, poor growth, respiratory illness, hospital readmissions, visual deficits, cerebral palsy, sensori-neural disability and cognitive, educational and behavioural

\footnotetext{
* Correspondence: laskie@ctc.usyd.edu.au

'NHMRC Clinical Trials Centre, University of Sydney, (Parramatta Road),

Camperdown, (2050), Australia

Full list of author information is available at the end of the article
}

impairment [4]. Recent studies have highlighted specific health issues former very preterm infants may face in later life, including an increased risk of cardiovascular disease and hypertension, impaired glucose tolerance, impaired renal function and abnormal respiratory function [5-9]. Very preterm infants account for a high proportion of the costs and disability from neonatal intensive care [10]. Reducing these morbidities would enhance quality of life for these infants and benefit their families and communities [11].

Oxygen is the most common therapy used in the care of very preterm infants. It has been associated with

\section{Biomed Central}


significant improvements in neonatal survival and disability [12]. However, preterm infants are highly sensitive to the harmful biochemical and physiological effects of supplemental oxygen. Toxic oxygen radicals are increased in hyperoxaemia [13] and in re-oxygenation after hypoxaemia. Preterm infants are vulnerable to oxidative stress because they lack antioxidant protection [13] from plasma radical scavengers such as beta- carotene, antioxidant enzymes, such as glutathione peroxidase, and their red cells lack superoxide dismutase.

Hyperoxaemia can constrict or obliterate vessels in an immature eye and brain, causing ischaemic injury [13]. Of survivors born at less than 28 weeks' gestation, $49 \%$ have retinopathy of prematurity (ROP), $12.4 \%$ have severe (Grade III or IV) ROP, $86 \%$ of these have surgery [2], but about $10 \%$ of those treated become blind. New recommendations have resulted in more infants with severe ROP having laser surgery [14].

High inspired oxygen contributes to bronchopulmonary dysplasia $[15,16]$. Oxidative damage to premyelinating oligodendrocytes in cerebral white matter is proposed as a mechanism of periventricular leukomalacia [17] which has been correlated with cerebral palsy. In preterm infants, oxygen reduces cerebral blood flow velocity independently of the effects of hypocapnia or hypotension [18].

Hyperoxaemia in the first eight days has been associated with twice the odds of cerebral palsy at 2 years [19]. In this study, the adjusted odds of cerebral palsy increased eightfold for infants with the highest versus the lowest quintile of exposure to hyperoxaemia, indicating a dose-response effect. Importantly, hyperoxaemia was defined as arterial oxygen above $60 \mathrm{~mm} \mathrm{Hg}$, in contrast with the long accepted upper limit of 80 $\mathrm{mm} \mathrm{Hg}[20,21]$.

Less exposure to oxygen is a simple strategy that could reduce oxidative stress and tissue injury and prevent morbidity in very preterm infants. In healthy preterm infants breathing air, arterial oxygen saturation $\left(\mathrm{SpO}_{2}\right)$ is $85-98 \%$. However, for infants requiring supplemental oxygen, the optimum range of arterial oxygen to minimise organ damage, without causing hypoxic injury, remains unknown.

\section{Summary of existing evidence}

The first case of ROP was reported in 1942. By 1954, ROP had blinded about 10,000 infants [22,23]. In 1954-56, three randomised trials, enrolling 341 infants, proved that breathing unrestricted concentrations of inspired oxygen was a major cause of ROP [24]. As arterial oxygen levels were not able to be measured, the concentration of inspired oxygen could not be targeted to meet each baby's needs. Following these findings, premature infants were restricted to breathing less than $40 \%$ inspired oxygen in order to prevent ROP. In the next 20 years over 150,000 premature babies died of hypoxic respiratory failure [12,25-27]. It is estimated that for every infant whose sight was saved, 16 died $[12,22,24]$ and many others developed spastic diplegia [26].

The Supplemental Therapeutic Oxygen for Prethreshold Retinopathy of Prematurity (STOP ROP) trial [28] used pulse oximetry to target lower (89-94\%) or higher (96-99\%) $\mathrm{SpO}_{2}$ in 649 preterm infants with pre-threshold ROP. The higher range caused more adverse respiratory events, including pneumonia, chronic lung disease requiring oxygen and diuretic therapy. There was no statistically significant difference in the rate of progression to threshold ROP. In the Benefits of Oxygen Saturation Targeting (BOOST) trial [29], 358 infants born at less than 30 weeks' gestation were randomly assigned, from 3 weeks or more after birth until they breathed air, to target a $\mathrm{SpO}_{2}$ range of either $91-94 \%$ or 95-98\%. This trial found no evidence that higher $\mathrm{SpO}_{2}$ targeting improved growth or development, but it did increase days of oxygen therapy and use of health care resources. Masked, adjusted oximeters were used in this trial so that some were adjusted to display masked values $2 \%$ lower than actual $\mathrm{SpO}_{2}$, and others displayed masked values $2 \%$ higher. Staff were unaware of actual $\mathrm{SpO}_{2}$ and targeted a masked range of $93-96 \%$. The authors concluded that further large randomised trials were needed to determine how targeting different $\mathrm{SpO}_{2}$ levels from the day of birth affects ROP, chronic lung disease, growth, disability and mortality $[22,29]$.

An early cohort study, reported in 1977 , was unable to establish a relationship between arterial oxygen tension

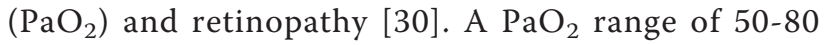
$\mathrm{mm} \mathrm{Hg}$ became widely accepted as an appropriate level to target $[20,21,31]$, but was based on professional consensus rather than evidence. A later study confirmed that ROP occurred more often with longer periods of time with a $\mathrm{PaO}_{2}$ above $80 \mathrm{~mm} \mathrm{Hg}$ [32], but did not determine if another limit was safer. Oximeters measuring functional $\mathrm{SpO}_{2}$ display values about $1.5 \%$ higher than those measuring fractional $\mathrm{SpO}_{2}$ [33]. Normal fetal oxygen saturation is $70-80 \%$ [34]. In transposing oxygen tensions of 50-80 mm $\mathrm{Hg}$ into equivalent arterial oxygen saturation, most clinicians have targeted functional $\mathrm{SpO}_{2}$ 90-95\% (the mid range of what is considered physiological) with a minimum of $85 \%$ [35].

In a more recent cohort study, Tin et al [34] showed that lower $\mathrm{SpO}_{2}$ correlated with improved short term respiratory and growth outcomes in infants born at less than 28 weeks' gestation. Babies in the neonatal intensive care units (NICU) targeting $\mathrm{SpO}_{2} 70-90 \%$ had $\mathrm{ROP}$ surgery less often than those in the NICUs targeting $\mathrm{SpO}_{2}$ 88-98\% (6.2\% v 27.2\%, 80\% relative risk reduction (RRR), $\mathrm{p}<0.01)$. Survivors were ventilated less often 
(13.9 v 31.4 days), fewer needed oxygen at 36 weeks' postmenstrual age (18\% v 46\%, 61\% RRR), and fewer were below the 3 rd centile for weight at discharge $(17 \%$ $v 45 \%, 62 \%$ RRR) (all p < 0.01) while survival (52\% v $53 \%)$ and cerebral palsy $(15 \% v 17 \%)$ at one year were similar [34].

Anderson et al [35] reported less Grade III/IV ROP $(2.4 \% v 5.5 \%, \mathrm{p}<0.001)$ and less ROP surgery $(1.3 \% v$ $3.3 \%, 61 \%$ RRR, $\mathrm{p}<0.037$ ) in NICUs with functional $\mathrm{SpO}_{2}$ upper limits of $\leq 92 \%$ vs $>92 \%$. Sun and colleagues [36] studied 1544 infants weighing $<1000 \mathrm{~g}$ in NICUs with upper $\mathrm{SpO}_{2}$ limits of $\leq 95 \% v>95 \%$. NICUs with $\leq 95 \%$ upper limits had less Grade III ROP (10\% v 29\%), surgery (4\% v 12\%, 67\% RRR), chronic lung disease (27\% $v 53 \%, 49 \%$ RRR) (all p < 0.001) and similar mortality (17\% $v 24 \%)$. Chow et al [37] found that a functional $\mathrm{SpO}_{2}$ of $83-90 \%$ was associated with less Grade III/IV ROP than an $\mathrm{SpO}_{2}$ of $90-98 \%$ in historical controls. This study found that from 1998 to 2001, severe ROP fell from $12.5 \%$ to $2.5 \%$ ( $80 \%$ RRR, $\mathrm{p}=0.01)$ and $\mathrm{ROP}$ surgery declined from $7.5 \%(6 / 80)$ to zero $(0 / 188)(100 \%$ RRR, $p=0.0006)$. These cohort studies thus suggest that lower $\mathrm{SpO}_{2}$ may reduce ROP surgery by $61-100 \%$; chronic lung disease by 49-61\%; and poor growth by $62 \%$. Effects on mortality and long term sensori-neural outcome remain unknown and could be beneficial or harmful.

There are two opposing concerns. Less inspired oxygen (targeting $\mathrm{SpO}_{2}<90 \%$ ) may increase patent ductus arteriosus, pulmonary vascular resistance and apnoea, and impair survival and neuro-development [38-40]. More inspired oxygen (targeting $\mathrm{SpO}_{2}>90 \%$ ) may increase severe ROP and chronic lung disease [16,34-37]. After recent studies [34-37], more NICUs are adopting a lower $\mathrm{SpO}_{2}$ policy. This trend may increase before the risks and benefits are determined. The disastrous mistakes of the 1950s [16,18,23,25,27] show how rapidly opinions can shift, destroying the chance of obtaining reliable evidence.

Worldwide demands to resolve the dilemma are intensifying. In 2003, an eminent international group of over 30 trialists, bio-statisticians, neonatologists, ophthalmologists and developmental paediatricians was convened to conduct the NeOProM (Neonatal Oxygenation Prospective Meta-analysis) Collaboration. In December 2003, the NeOProM project was outlined in a commentary in Pediatrics [41].

There are five trials which are currently in progress to assess this question (see Table 1). Each of these trials will recruit between 300 and 1300 babies. However, none individually will be able to exclude the possibility that the expected valuable short term benefits associated with giving babies less oxygen are not associated with a small but significant $4 \%$ increase in death or serious neurosensory disability in survivors, from an average baseline of $42 \%$. Reliably excluding a small, but clinically important, difference in death or severe disability of $4 \%$ requires over 5000 infants, which no single trial is able to recruit in a timely fashion. For example the Australian BOOST II trial which plans to recruit approximately 1200 infants will be able to exclude a difference of $8 \%$ (from $37 \%$ to $45 \%$ or from $37 \%$ to $29 \%$ ) in the major composite outcome of death or severe disability in survivors.

For this reason, the Principal Investigators of the participating trials have pledged their support for a prospective meta-analysis (PMA) of individual patient data (IPD) from each of these studies. These five trials are sufficiently similar in terms of the population enrolled, interventions tested and outcomes measured to allow the collection and combination of IPD from each trial into a large, core, common dataset. Combining the data from several trials of similar design using PMA methodology differs from a standard meta-analysis of trial results in several important ways.

A prospective meta-analysis (PMA) is a meta-analysis where studies (usually randomised controlled trials) are identified, evaluated, and determined to be eligible before the results of included studies are known or published. This methodology can help avoid some of the potential biases inherent in standard, retrospective meta-analyses. These can include publication bias, selection bias of subjects and trials; and bias due to post hoc selection of study questions, eligibility criteria, outcome definitions or subgroups $[42,43]$.

The key features of PMA are to prospectively define and clearly specify the objectives, research question(s), specific aims, hypotheses, subject eligibility criteria, subgroups, predictors, outcomes (primary and secondary) and the analysis plans of eligible studies in advance of knowing or publishing individual trial results [42]. PMA provides more reliable estimates of treatment effects through prospectively planned combined analysis of large-scale randomised controlled trials. In addition to having greater power to detect meaningful modest differences in less frequent, clinically important outcomes, PMA provides adequate power to evaluate events in important subgroups underrepresented in smaller trials. Thus, PMA provides the same strengths as a single largescale multicentre randomised study.

Another advantage is that PMA provides greater, pragmatic flexibility in achieving the objectives of a single mega-trial. Through prospectively planned combined analysis of large, randomised trials, PMA accommodates funding agency variations, reduces costs to an individual funding agency for a mega-trial, whilst providing the same strengths and benefits of a single large randomised study. In this regard, PMA sets an important precedent 
Table 1 Eligible trials collaborating in the NeOProM initiative at December 2009

\begin{tabular}{lllllll}
\hline $\begin{array}{l}\text { Trial } \\
\text { acronym }\end{array}$ & Country & $\begin{array}{l}\text { Planned } \\
\mathbf{n}\end{array}$ & $\begin{array}{l}\text { Recruitment start } \\
\text { date }\end{array}$ & $\begin{array}{l}\text { Recruitment finish } \\
\text { date }\end{array}$ & $\begin{array}{l}\text { Follow-up data } \\
\text { finalised }\end{array}$ & Planned date of publication \\
\hline SUPPORT & USA & 1310 & April 2005 & April 2009 & April 2011 & $\begin{array}{l}\text { May 2010 (short term outcomes) } \\
\text { Dec 2011 (longer term follow-up) }\end{array}$ \\
BOOST II & Australia & 1200 & Mar 2006 & Dec 2010 & Dec 2012 & May 2013 \\
BOOST-NZ & NZ & 320 & Sep 2006 & Dec 2009 & Dec 2011 & Dec 2012 \\
COT & Canada & 1200 & Jan 2007 & Jul 2010 & Dec 2011 & Jun 2012 \\
BOOST II-UK & UK & 1200 & Sep 2007 & Feb 2011 & Feb 2013 & Sep 2013 \\
\hline
\end{tabular}

for future large neonatal trials. PMAs encourage uniformity in common protocol items amongst trials, including data collection and outcome definitions, whilst permitting flexibility in pre-specified protocol details and funding regulations. To protect the integrity of each individual trial, the main PMA results are published only after the principal results of each individual trial have been published. This methodology also has the flexibility to allow questions to be added after the PMA protocol has been developed provided the additional studies or questions are chosen in a manner masked to the results of included trials [42].

By establishing collaboration between trialists of the eligible studies, it is possible to collect individual patient data (IPD) and incorporate it into the meta-analysis. Using data collected from each individual within a trial, rather than relying on aggregate data from each trial, can improve the power and scope of the meta-analysis. In particular, a meta-analysis using IPD can enable more flexible and detailed subgroup analyses [44,45].

This will be the first-ever neonatal prospective metaanalysis. However, the methodology has been used extensively in other areas of health care, particularly in cardiovascular disease [43] and cancer [46]. Large PMAs such as the Blood Pressure Lowering Treatment Trialists Collaboration recently published [47] demonstrate how this methodology can be used very effectively to assess treatment effects in specific subgroups.

The Neonatal Oxygenation Prospective Meta-analysis (NeOProM) Collaboration will be coordinated in Sydney, Australia. The Principal Investigators of each of the trials involved in NeOProM will be members of the Collaboration's Management Committee. Thus, this is an opportunity to adapt the methodologies of prospective meta-analysis and individual patient data meta-analysis, already well-established in other health care fields, for use in answering important neonatal questions.

\section{Objectives}

The primary question to be addressed by this study is: does targeting a lower oxygen saturation range in extremely preterm infants from birth or soon after, increase or decrease the composite outcome of death or major disability in survivors by $4 \%$ or more?

\section{Hypotheses}

Compared with a functional oxygen saturation level $\left(\mathrm{SpO}_{2}\right)$ of $91-95 \%$, targeting $\mathrm{SpO}_{2} 85-89 \%$ within 24 hours of birth is associated with $<4 \%$ absolute risk difference from $42 \%[4,10]$ to $46 \%$ or from $42 \%$ to $38 \%$ ( $10 \%$ relative risk increase or reduction (RRR)) in mortality and major disability by 2 years corrected age (defined as gestational age plus chronological age).

\section{Sample size}

A total sample size of 5230 (including infants from the SUPPORT, BOOST II Australia, BOOST-NZ, BOOST II UK, COT trials) (see Table 1 for trial details) would have a $80 \%$ power to detect a $4 \%$ difference in the primary outcome: death or major disability. The precision of the combined sample size will ensure that a $4 \%$ increase in death or major disability could be detected (for example from $42 \%$ to $46 \%$ ), with $95 \%$ confidence that the true result was an increase in this outcome from $42 \%$ to between $43.7 \%$ and $48.7 \%$ (RR1.10, 95\% CI 1.04-1.16).

\section{Methods/Design}

The Principal Investigators of all eligible trials were approached and have agreed to participate in the $\mathrm{NeO}$ ProM Collaboration and provide the relevant individual patient data upon completion of their respective trials. A common data collection form, coding sheet and detailed analysis plan will be developed and agreed by members of the Collaboration prior to the collection and analysis of data from the individual trials.

\section{Eligibility criteria for studies to be included}

Studies will be included if they are randomised trials. The level of allocation concealment within each trial will be assessed according to the criteria outlined in the Cochrane Handbook [42], and only those trials with adequate allocation concealment will be eligible. Participating trials are required to register on a publicly 
accessible trials registry before enrolment of the first patient [44].

\section{Participants}

Participants in the eligible trials will be infants born before 28 weeks' gestation and enrolled within 24 hours of birth.

\section{Interventions}

The intervention will be random assignment to either a lower $\left(\mathrm{SpO}_{2}\right.$ 85-89\%) or higher $\left(\mathrm{SpO}_{2}\right.$ 91-95\%) functional oxygen saturation target range from birth, or soon thereafter, for durations as specified in each trial protocol (see Table 2). Intervention assignment must be masked to parents, care-givers and outcome assessors by the use of pulse oximeters that have been adjusted to display either $3 \%$ above or below the infant's actual saturation value, within the $85-95 \%$ oxygen saturation range.

\section{Outcomes}

Analysis will be of all infants ever randomised and will be based on intention-to-treat. Binary outcomes will be analysed using log-binomial regression models adjusting for trial differences by including the trial variable in the model specification. Exponentiating the parameter estimate for treatment from a log-binomial regression model produces a relative risk for treatment. Continuous normally distributed endpoints will be analysed using a linear fixed effects model. Additionally the treatment by trial interaction will be assessed to investigate possible heterogeneity of treatment effects [48]. The overall estimated mean and standard deviation within each treatment group will be presented along with the mean difference in treatment effect and its 95\% confidence interval with $p$ value. If the data do not meet the assumptions for the model then transformations or alternative models will be investigated. If appropriate, multivariable regression modeling will be undertaken as exploratory analyses to assess treatment by covariate interactions. A detailed analysis plan will be developed as a separate document.

\section{Primary outcome}

- composite outcome of death or major disability by 18-24 months corrected age (gestational age plus chronological age). Major disability is any of the following: Bayley III Developmental Assessment cognitive score $<85$ and/or language score $<85$ [49], severe visual loss (cannot fixate or is legally blind: $<6 / 60$ vision, $1.3 \operatorname{logMAR}$ in both eyes) [50], cerebral palsy with Gross Motor Function Classification System (GMFCS) level 2 [51] or higher or Manual Ability Classification System (MACS) level 2 or higher [52] at 18-24 months postmenstrual age, or deafness requiring hearing aids.

\section{Additional outcomes}

- ROP treatment by laser photocoagulation or cryotherapy (performed if Type I ROP or threshold ROP occurs) [14]

- measures of respiratory support, defined as (a) supplemental oxygen requirement at 36 weeks' postmenstrual age (see Table 2), (b) days of endotracheal intubation (c) days of continuous positive airway pressure (CPAP), (d) days of supplemental oxygen, (e) days on home oxygen

- patent ductus arteriosus diagnosed by ultrasound and requiring medical treatment

- patent ductus arteriosus requiring surgical treatment

- necrotising enterocolitis requiring surgery

- weight at birth, 36 weeks' postmenstrual age, discharge home and 18-24 months corrected age

- re-admissions to hospital up to 18-24 months corrected age

- cerebral palsy with GMFCS level 2 or higher or MACS level 2 or higher at 18-24 months corrected age

- blindness (<6/60 vision, $1.3 \log$ MAR in both eyes)

- deafness requiring hearing aids

- quantitative Bayley III scores

- death

\section{Planned subgroup analyses}

The effect of the intervention (higher versus lower oxygen saturation targeting) may be differential due to certain characteristics of either the infant or the way the intervention was delivered. These possible effects will be explored by the following subgroup analyses.

\section{a. Patient baseline characteristics}

- gestational age ( $<26$ weeks/>26 weeks)

- inborn or outborn status

- antenatal steroids (any: yes/no)

- gender (male/female)

- small for gestational age (yes/no)

- multiples (singleton/multiple)

- mode of delivery (vaginal/caesarean)

b. Intervention characteristics

- time of intervention commencement $(<6$ hours/ $>6$ hours)

- oximeter adjustment algorithm (original or revised)

\section{Planned sensitivity analyses}

To assess whether results are robust to different methods of analysis and trial quality the following sensitivity analyses will be conducted:

- comparison of analyses using random effects and fixed effect models 
Table 2 Characteristics of randomised trials included in NeOProM Collaboration

\begin{tabular}{|c|c|c|c|c|c|}
\hline $\begin{array}{l}\text { Trial } \\
\text { acronym }\end{array}$ & BOOST II-Australia & BOOST II-UK & BOOST-NZ & SUPPORT & COT \\
\hline $\begin{array}{l}\text { Registration } \\
\text { number }\end{array}$ & ACTRN12605000055606 & ISRCTN00842661 & ACTRN12605000253606 & NCT00233324 & ISRCTN62491227 \\
\hline $\begin{array}{l}\text { Planned } \\
\text { sample size }\end{array}$ & 1200 & 1200 & 320 & 1310 & 1200 \\
\hline $\begin{array}{l}\text { Countries of } \\
\text { recruitment }\end{array}$ & Australia & United Kingdom & New Zealand & United States & $\begin{array}{l}\text { Canada, USA, Argentina, } \\
\text { Germany, Israel, Finland }\end{array}$ \\
\hline Participants & $\begin{array}{l}\text { Infants }<28 \text { wks } \\
\text { gestation inborn or } \\
\text { outborn }<24 \text { hrs old }\end{array}$ & $\begin{array}{l}\text { Infants }<28 \text { wks } \\
\text { gestation }<12 \text { hrs old } \\
\text { ( } 24 \text { hrs if outborn) }\end{array}$ & $\begin{array}{l}\text { Infants }<28 \text { wks } \\
\text { gestation inborn or } \\
\text { outborn }<24 \text { hrs old }\end{array}$ & $\begin{array}{l}\text { Infants } 24-27 \text { wks } \\
\text { gestation }<2 \text { hrs old }\end{array}$ & $\begin{array}{l}\text { Infants } 23 \text { 0/7-27 6/7 wks } \\
\text { gestation < } 24 \text { hrs old }\end{array}$ \\
\hline Masked? & Yes & Yes & Yes & Yes & Yes \\
\hline Intervention & $\begin{array}{l}\text { Lower oxygen saturation } \\
(85 \%-89 \%)\end{array}$ & $\begin{array}{l}\text { Lower oxygen saturation } \\
(85 \%-89 \%)\end{array}$ & $\begin{array}{l}\text { Lower oxygen saturation } \\
(85 \%-89 \%)\end{array}$ & $\begin{array}{l}\text { Lower oxygen saturation } \\
(85 \%-89 \%)\end{array}$ & $\begin{array}{l}\text { Lower oxygen saturation } \\
(85 \%-89 \%)\end{array}$ \\
\hline Comparator & $\begin{array}{l}\text { Higher oxygen saturation } \\
(91 \%-95 \%)\end{array}$ & $\begin{array}{l}\text { Higher oxygen saturation } \\
(91 \%-95 \%)\end{array}$ & $\begin{array}{l}\text { Higher oxygen saturation } \\
(91 \%-95 \%)\end{array}$ & $\begin{array}{l}\text { Higher oxygen } \\
\text { saturation (91\%-95\%) }\end{array}$ & $\begin{array}{l}\text { Higher oxygen saturation } \\
(91 \%-95 \%)\end{array}$ \\
\hline $\begin{array}{l}\text { Intervention } \\
\& \\
\text { comparator } \\
\text { duration }\end{array}$ & $\begin{array}{l}\text { Oximeter applied asap } \\
\text { after admission to } \mathrm{NICU} \text {, } \\
\text { continued for minimum } \\
2 \text { wks. Thereafter } \\
\text { continued until } 36 \text { wks } \\
\text { corrected age or } \mathrm{SpO}_{2}> \\
96 \% \text { in room air for } 95 \% \\
\text { of time over } 3 \text { days. }\end{array}$ & $\begin{array}{l}\text { Oximeter applied from } \\
\text { randomisation until } \\
\text { postmenstrual age (PMA) } \\
\text { of } 36 \text { wks or until baby } \\
\text { is breathing air. All } \\
\text { monitoring at any time } \\
\text { prior to } 36 \text { wks to be } \\
\text { done using study } \\
\text { oximeter. BPD defined at } \\
36 \text { wks using a } \\
\text { physiological test. }\end{array}$ & $\begin{array}{l}\text { Oximeter applied asap } \\
\text { after admission to NICU, } \\
\text { continued for minimum } \\
2 \text { wks. Thereafter } \\
\text { continued until } 36 \text { wks } \\
\text { corrected age or } \mathrm{SpO}_{2}> \\
96 \% \text { in room air for } 95 \% \\
\text { of time over } 3 \text { days. }\end{array}$ & $\begin{array}{l}\text { Oximeter applied within } \\
2 \text { hrs following } \\
\text { admission to NICU until } \\
\text { infant has been in room } \\
\text { air for } 72 \text { hrs or until } 36 \\
\text { wks corrected age, } \\
\text { assessed by physiologic } \\
\text { oxygen test. }\end{array}$ & $\begin{array}{l}\text { Oximeter applied from } \\
\text { day of birth until a } \\
\text { minimum } 36 \text { wks PMA. If } \\
\text { breathing room air } \\
\text { without any form of } \\
\text { respiratory assistance } \\
\text { from } 35 \text { wks PMA } \\
\text { onward, study oximetry } \\
\text { discontinued at a } 36 \text { wks } \\
\text { PMA. If receiving any } \\
\text { form of respiratory } \\
\text { assistance and/or oxygen } \\
\text { therapy from } 35 \text { wks } \\
\text { PMA onward study } \\
\text { oximetry continues until } \\
40 \text { wks PMA. Study } \\
\text { oximetry stopped at any } \\
\text { time before } 40 \text { wks PMA } \\
\text { if baby discharged home } \\
\text { (with or without } \\
\text { respiratory assistance } \\
\text { and/or oxygen). }\end{array}$ \\
\hline $\begin{array}{l}\text { Primary } \\
\text { outcome(s) }\end{array}$ & $\begin{array}{l}\text { Death or survival with } \\
\text { major disability at } 2 \text { yrs } \\
\text { corrected for gestation. } \\
\text { Major disability defined } \\
\text { as having any of the } \\
\text { following: } \\
{ }^{*} \text { cognitive score }<70 \text { on } \\
\text { BSID-3 } \\
{ }^{*} \text { severe visual loss } \\
{ }^{*} \text { cerebral palsy with } \\
\text { inability to walk at } 2 \text { yrs } \\
{ }^{*} \text { deafness requiring } \\
\text { hearing aids }\end{array}$ & $\begin{array}{l}\text { Death or survival with } \\
\text { major disability at } 2 \text { yrs } \\
\text { corrected for gestation. } \\
\text { Major disability defined } \\
\text { as having any of the } \\
\text { following: } \\
\text { * cognitive score < } 70 \text { on } \\
\text { BSID-3 } \\
\text { * severe visual loss } \\
\text { * cerebral palsy with } \\
\text { inability to walk at } 2 \text { yrs } \\
\text { * deafness requiring (or } \\
\text { too severe to benefit } \\
\text { from) hearing aids }\end{array}$ & $\begin{array}{l}\text { Death or survival with } \\
\text { major disability at } 2 \text { yrs } \\
\text { corrected for gestation. } \\
\text { Major disability is defined } \\
\text { as having any of the } \\
\text { following: } \\
{ }^{*} \text { cognitive score }<70 \text { on } \\
\text { BSID-3 } \\
\text { * severe visual loss } \\
{ }^{*} \text { cerebral palsy with } \\
\text { inability to walk at } 2 \text { yrs } \\
\text { * deafness requiring } \\
\text { hearing aids }\end{array}$ & $\begin{array}{l}\text { 1. Death or survival with } \\
\text { neurodevelopmental } \\
\text { outcome at } 18-22 \text { mths } \\
\text { corrected age. } \\
\text { 2. Survival without } \\
\text { severe ROP (threshold } \\
\text { ROP and/or the need for } \\
\text { surgical intervention) }\end{array}$ & $\begin{array}{l}\text { Death or survival with } \\
\text { major disability at } 18-21 \\
\text { mths Major disability } \\
\text { defined as having any of } \\
\text { the following: } \\
\text { * cognitive score }<85 \\
\text { and/or language score } \\
<85 \text { on BSID-3 } \\
\text { * severe visual loss } \\
\text { * cerebral palsy with } \\
\text { inability to crawl or walk } \\
\text { independently } \\
\text { * deafness requiring } \\
\text { hearing aids }\end{array}$ \\
\hline
\end{tabular}

- analysis of outcomes weighted by degree of oxygen saturation separation between treatment and control [53]

\section{Ethics and management issues}

\section{Search methods for identification of studies}

Efforts to identify any ongoing trials that may be eligible for participation in this PMA included searches for published protocols on online databases such as
Medline and Embase as well as internet searches for non-peer reviewed articles and other publications using Google. Further efforts included informing networks of the proposed PMA and approaching presenters at relevant conferences and network meetings. Ongoing trials will only be permitted to join the PMA prior to the results of any of the participating trials being made publicly available. 


\section{Data monitoring procedures}

Because different oxygen targets may have competing risks, it is essential that sufficiently large numbers of recruits across all trials are allowed to accumulate to be able to demonstrate net clinical benefit or harm. Each participating trial will have its own Data and Safety Monitoring Committee (DSMC). The Principal Investigators of each trial will seek to ensure that the Chairperson of their own DSMC knows of the existence of the other participating trials and their DSMC Chairpersons so that communication can occur between them if required. The NeOProM Management Committee will give consideration to any requests from DSMC Chairpersons for sharing of de-identified data (either aggregate or individual patient data) should the need arise. There are 'in principle' plans to update the PMA data at regular intervals as longer term follow-up data become available but (as of December 2009) there are no formalised plans yet agreed.

\section{Project management}

Membership of the NeOProM Collaboration includes representative(s) from each of the trials contributing data to the project with an accompanying project coordination and data management structure. An international Steering Group has been established with all collaborating trials being represented as well as experts in the fields of PMA, IPD meta-analysis, data monitoring and trial compliance and design being included. Project coordination and data management/analysis are coordinated from the NHMRC Clinical Trials Centre, University of Sydney, Australia.

\section{Funding}

Funding for the NeOProM Collaboration has, and will continue to be, sought from relevant funding agencies. Each individual trial is receiving funding from their own respective national government research funding bodies, including the National Institutes of Health (United States), National Health and Medical Research Council (Australia), Health Research Council (New Zealand), Medical Research Council (United Kingdom) and Canadian Institutes of Health Research (Canada).

\section{Publication policy}

Each of the participating trials will be able to publish their main individual trial results prior to publication of the final PMA results. Each of the participating trials will seek to include reference to the NeOProM Collaboration in the published abstract and, if possible, in the text of their main individual trial publication. The main manuscript will be prepared by the NeOProM Steering Group, before circulation to the full Collaborative Group for comment and revision. Publications using these data will be authored on behalf of the NeOProM Collaboration, either with specific named authors, or on behalf of the Collaboration as a whole, as agreed by the Steering
Group. Names of other participating Collaborators will be acknowledged in an appropriate section of the manuscript. Subsequent analyses and publications will only be undertaken via collaboration with, and with the approval of, the NeOProM Collaboration Steering Group.

\section{Ethical considerations}

Parents of participants in the individual trials have previously consented to participation by their children in their respective trial. The data for this project are to be used for the purpose for which they were originally collected and are available through an agreement between all trialists of the NeOProM Collaboration. These trialists remain the custodians of their original individual trial data at all times and have the right to withdraw some or all of their data from the analyses. Data are provided on the stipulation that all trials have received ethical clearances from their relevant bodies.

\section{Discussion}

Results should be available by 2014 .

\section{Abbreviations}

NeOProM: Neonatal Oxygenation Prospective Meta-analysis; PMA: prospective meta-analysis; $\mathrm{ROP}$ : retinopathy of prematurity; $\mathrm{SpO}_{2}$ : arterial oxygen saturation; $\mathrm{PaO}_{2}$ : arterial oxygen tension; NICU: Neonatal Intensive Care Unit; RRR: relative risk ratio; IPD: individual patient data; GMFCS: Gross Motor Function Classification System; MACS: Manual Ability Classification System; DSMC: Data and Safety Monitoring Committee.

\section{Acknowledgements}

Members of the NeOProM Collaborative Group who have contributed to the development of this protocol (in alphabetical order):

Lisa M Askie, Peter Brocklehurst, Wally Carlo, Cynthia Cole, Lorrie Costantini, Brian A Darlow, Abhik Das, Peter Davis, Lex Doyle, Neil Finer, Marie Gantz, Henry Halliday, Edmund Hey, Rosemary Higgins, Neil Marlow, Colin Morley, Wade Rich, Robin Roberts, Barbara Schmidt, John Simes, Ben Stenson, William Tarnow-Mordi, Jayne F Tierney, Win Tin, Kris Zaterka-Baxter. We would also like to acknowledge the funding support of the NHMRC Clinical Trials Centre, University of Sydney, Australian National Health and Medical Research Council, The Health Research Council of New Zealand, The National Institutes of Health (USA) and the Canadian Institutes of Health Research; Kylie Hunter and Charlene Thornton for research assistant support; David Henderson-Smart, Jack Sinclair, Gabriel Duc and the late Bill Silverman and Edmund Hey for their wise counsel on this topic over many years.

\section{Author details}

${ }^{1}$ NHMRC Clinical Trials Centre, University of Sydney, (Parramatta Road), Camperdown, (2050), Australia. ${ }^{2}$ National Perinatal Epidemiology Unit (NPEU), University of Oxford, (Old Road Campus), Oxford, (OX3 7LF), UK.

${ }^{3}$ Christchurch School of Medicine, University of Otago, (Riccarton Avenue), Christchurch, (8140), New Zealand. ${ }^{4}$ Division of Neonatology, University of California San Diego (UCSD) Medical Center, (West Arbor Drive), San Diego, (92103), USA. ${ }^{5}$ Children's Hospital of Philadelphia, University of Pennsylvania, (Spruce Street), Philadelphia, (19104), USA. ${ }^{6}$ Neonatal Trials Group, McMaster University, (Concession Street), Hamilton, (L8V 1C3), Canada. ${ }^{7}$ Westmead Hospital, University of Sydney, (Cnr Hawkesbury and Darcy Roads), Westmead, (2145), Australia. ${ }^{8}$ Children's Hospital at Westmead, University of Sydney, (Cnr Hawkesbury Road and Hainsworth Street), Westmead, (2145), Australia.

\section{Authors' contributions}

This protocol document was developed by the authors in consultation with members of the NeOProM Collaboration as listed in the Acknowledgements section below. All members of this group were sent draft versions and 
invited to comment and contribute changes. All authors read and approved the final manuscript.

\section{Competing interests}

The authors declare that they have no competing interests.

Received: 1 June 2010 Accepted: 17 January 2011

Published: 17 January 2011

\section{References}

1. Centre for Epidemiology and Research, New South Wales Department of Health: New South Wales Mothers and Babies 2005. NSW Public Health Bull 2007, 18:S-1.

2. Abeywardana S: The report of the Australian and New Zealand Neonatal Network, 2005 Sydney: ANZNN; 2007.

3. Victorian Infant Collaborative Study Group: Economic outcome for intensive care infants of birthweight 500-999 $\mathrm{g}$ born in Victoria in the post surfactant era. J Paediatr Child Health 1997, 33:202-208.

4. Anderson P, Doyle LW, Victorian Infant Collaborative Study Group: Neurobehavioral outcomes of school-age children born extremely low birth weight or very preterm in the 1990s. JAMA 2003, 289:3264-3272.

5. Doyle LW, Faber B, Callanan C, Freezer N, Ford GW, Davis NM: Bronchopulmonary Dysplasia in Very Low Birth Weight Subjects and Lung Function in Late Adolescence. Pediatrics 2006, 118:108-113.

6. Hack M: Young adult outcomes of very-low-birth-weight children. Semin Fetal Neonat Med 2006, 11:127-137.

7. Halvorsen T, Skadberg BT, Eide GE, Røksund OD, Carlsen KH, Bakke P: Pulmonary outcome in adolescents of extreme preterm birth: a regional cohort study. Acta Paediatr 2004, 93:1294-1300.

8. Hovi P, Andersson S, Eriksson JG, Jarvenpaa A, Strang-Karlsson S, Makitie O, Kajantie E: Glucose Regulation in Young Adults with Very Low Birth Weight. N Engl J Med 2007, 356:2053-2063.

9. Rodríguez-Soriano J, Aguirre $\mathrm{M}$, Oliveros $\mathrm{R}$, Vallo A: Long-term renal followup of extremely low birth weight infants. Pediatr Nephrol 2005, 20:579-584.

10. Sutton L, Bajuk B, New South Wales Neonatal Intensive Care Unit Study Group: Population-based study of infants born at less than 28 weeks' gestation in New South Wales, Australia, in 1992-3. Paediatr Perinat Epidemiol 1999, 13:288-301.

11. Saigal S, Burrows E, Stoskopf BL, Rosenbaum PL, Streiner D: Impact of extreme prematurity on families of adolescent children. J Pediatr 2000, 137:701-706.

12. Avery ME, Oppenheimer MD: Recent increase in mortality from hyaline membrane disease. Pediatrics 1960, 57:553-559.

13. Hellström A, Perruzzi $C$, Ju M, Engstrom E, Hard AL, Liu JL, AlbertssonWikland K, Carlsson B, Niklasson A, Sjodell L, et al: Low IGF-I suppresses VEGF-survival signaling in retinal endothelial cells: direct correlation with clinical retinopathy of prematurity. Proc Natl Acad Sci USA 2001, 98:5804-5808.

14. Early Treatment For Retinopathy Of Prematurity Cooperative Group: Revised indications for the treatment of retinopathy of prematurity: results of the early treatment for retinopathy of prematurity randomized trial. Arch Ophthalmol 2003, 121:1684-1694.

15. Jobe AH, Bancalari E: Bronchopulmonary dysplasia. Am J Respir Crit Care Med 2001, 163:1723-1729.

16. Warner BB, Stuart LA, Papes RA, Wispe JR: Functional and pathological effects of prolonged hyperoxia in neonatal mice. Am J Physiol 1998, 275 L110-117.

17. Haynes RL, Folkerth RD, Keefe RJ, Sung I, Swzeda LI, Rosenberg PA, Volpe JJ, Kinney $\mathrm{HC}$ : Nitrosative and oxidative injury to premyelinating oligodendrocytes in periventricular leukomalacia. J Neuropathol Exp Neurol 2003, 62:441-450.

18. Niijima S, Shortland DB, Levene MI, Evans DH: Transient hyperoxia and cerebral blood flow velocity in infants born prematurely and at full term. Arch Dis Child 1988, 63:1126-1130.

19. Collins MP, Lorenz JM, Jetton JR, Paneth N: Hypocapnia and other ventilation-related risk factors for cerebral palsy in low birth weight infants. Pediatr Res 2001, 50:712-719.

20. American Academy of Pediatrics, American College of Obstetricians and Gynecologists: Guidelines for Perinatal Care. 2 edition. Washington DC; 1988.
21. American Academy of Pediatrics, American College of Obstetricians and Gynecologists: Guidelines for Perinatal Care. 5 edition. IL: Elk Grove Village; 2002

22. Silverman WA: A cautionary tale about supplemental oxygen: the albatross of neonatal medicine. Pediatrics 2004, 113:394-396.

23. Silverman WA: Retrolental fibroplasia: a modern parable Grune \& Stratton; 1980

24. Askie LM, Henderson-Smart DJ: Restricted versus liberal oxygen exposure for preventing morbidity and mortality in preterm or low birth weight infants. Cochrane Db Syst Rev 2001, 4, Art. No.: CD001077.

25. Bolton DPG, Cross KW: Further observations on cost of preventing retrolental fibroplasia. Lancet 1974, 445-448

26. McDonald AD: The aetiology of spastic diplegia. A synthesis of epidemiological and pathological evidence. Dev Med Child Neuro 1964 11:277-285.

27. Cross KW: Cost of preventing retrolental fibroplasia? Lancet 1973, 954-956.

28. STOP ROP Investigators: Supplemental Therapeutic Oxygen for Prethreshold Retinopathy Of Prematurity (STOP-ROP), a randomized, controlled trial. I: primary outcomes. Pediatrics 2000, 105:295-310.

29. Askie LM, Henderson-Smart DJ, Irwig L, Simpson JM: Oxygen-saturation targets and outcomes in extremely preterm infants. N Engl J Med 2003, 349:959-967.

30. Kinsey VE, Arnold HJ, Kalina RE, Stern L, Stahlman M, Odell G, Driscoll JM, Elliott $J \mathrm{H}$, Payne J, Patz A: PaO2 levels and retrolental fibroplasia: a report of the cooperative study. Pediatrics 1977, 60:655-668.

31. Mclntosh N, Marlow N: High or low oxygen saturation for the preterm baby. Arch Dis Child Fetal Neonatal Ed 2001, 84:F149-F150.

32. Flynn JT, Bancalari E, Snyder ES, Goldberg RN, Feuer W, Cassady J, Schiffman J, Feldman HI, Bachynski B, Buckley E, et al: A cohort study of transcutaneous oxygen tension and the incidence and severity of retinopathy of prematurity. N Engl J Med 1992, 326:1050-1054.

33. Thilo EH, Andersen D, Wasserstein ML, Schmidt J, Luckey D: Saturation by pulse oximetry: comparison of the results obtained by instruments of different brands. J Pediatrics 1993, 122:620-626.

34. Tin W, Milligan DW, Pennefather P, Hey E: Pulse oximetry, severe retinopathy, and outcome at one year in babies of less than 28 weeks gestation. Arch Dis Child Fetal Neonatal Ed 2001, 84:F106-F110.

35. Anderson CG, Benitz WE, Madan A: Retinopathy of prematurity and pulse oximetry: a national survey of recent practices. J Perinatol 2004, 24:164-168.

36. Sun SC: Relation of target SpO2 levels and clinical outcome in ELBW infants on supplemental oxygen. Pediatr Res 2002, 51:350A.

37. Chow LC, Wright KW, Sola S: Can changes in clinical practice decrease the incidence of severe retinopathy in very low birth weight infants? Pediatrics 2003, 111:339-345.

38. Newburger JW, Silbert AR, Buckley LP, Fyler DC: Cognitive function and age at repair of transposition of the great arteries in children. $N$ Engl $J$ Med 1984, 310:1495-1499.

39. Skinner JR, Hunter S, Poets CF, Milligan DWA, Southall D, Hey EN: Haemodynamic effects of altering arterial oxygen saturation in preterm infants with respiratory failure. Arch Dis Child Fetal Neonatal Ed 1999, 80: F81-F87.

40. Subhedar NV, Shaw NJ: Changes in pulmonary arterial pressure in preterm infants with chronic lung disease. Arch Dis Child Fetal Neonatal Ed 2000, 82:F243-F247.

41. Cole CH, Wright KW, Tarnow-Mordi W, Phelps DL, Pulse Oximetry Saturation Trial for Prevention of Retinopathy of Prematurity Planning Study Group: Resolving our uncertainty about oxygen therapy. Pediatrics 2003, 112:1415-1419.

42. Alderson P, Green S, Higgins JPT, Eds: Cochrane Reviewers' Handbook 4.2.2 [updated March 2004]. The Cochrane Library, Issue 1 Chichester, UK: John Wiley \& Sons, Ltd; 2004

43. Simes RJ, on behalf of the PPP and CTT Investigators: Prospective metaanalysis of cholesterol-lowering studies: the Prospective Pravastatin Pooling (PPP) Project and the Cholesterol Treatment Trialists (CTT) Collaboration. Am J Cardiol 1995, 76:122C-126C.

44. World Medical Organization: Declaration of Helsinki. BMJ 1996, 313:1448-1449.

45. Review Manager (RevMan) [Computer program] Copenhagen: The Nordic Cochrane Centre, The Cochrane Collaboration; 2008. 
46. Efficacy of adjuvant fluorouracil and folinic acid in colon cancer: International Multicentre Pooled Analysis of Colon Cancer Trials (IMPACT) investigators. Lancet 1995, 345:939-944.

47. Blood Pressure Lowering Treatment Trialists' Collaboration: Effects of different blood-pressure-lowering regimens on major cardiovascular events: results of prospectively-designed overviews of randomised trials. Lancet 2003, 362:1527-1535.

48. Higgins JP, Thompson SG: Quantifying heterogeneity in a meta-analysis. Stat Med 2002, 21:1539-1558.

49. Bayley N: Bayley scales of infant and toddler development. Third edition. San Antonio, TX:Harcourt Assessment, Inc.; 2006.

50. Holmström G, Larsson E: Long-term follow-up of visual functions in prematurely born children-a prospective population-based study up to 10 years of age. $J$ AAPOS 2008, 12:157-162.

51. Morris C: Development of the Gross Motor Function Classification System (1997). Dev Med Child Neuro 2007, 49:644.

52. Eliasson A, Krumlinde-Sundholm L, Rösblad B, Beckung E, Arner M, Öhrvall A, Rosenbaum P: The Manual Ability Classification System (MACS) for children with cerebral palsy: scale development and evidence of validity and reliability. Dev Med Child Neuro 2006, 48:549-554.

53. Baigent C, Keech A, Kearney PM, Blackwell L, Buck G, Pollicino C, Kirby A, Sourjina T, Peto R, Collins R, et al: Efficacy and safety of cholesterollowering treatment: prospective meta-analysis of data from 90056 participants in 14 randomised trials of statins. Lancet 2005, 366:1267-1278.

\section{Pre-publication history}

The pre-publication history for this paper can be accessed here: http://www.biomedcentral.com/1471-2431/11/6/prepub

doi:10.1186/1471-2431-11-6

Cite this article as: Askie et al: NeOProM: Neonatal Oxygenation

Prospective Meta-analysis Collaboration study protocol. BMC Pediatrics 2011 11:6.

\section{Submit your next manuscript to BioMed Central and take full advantage of:}

- Convenient online submission

- Thorough peer review

- No space constraints or color figure charges

- Immediate publication on acceptance

- Inclusion in PubMed, CAS, Scopus and Google Scholar

- Research which is freely available for redistribution

Submit your manuscript at www.biomedcentral.com/submit 